\title{
Gene Transfer into Respiratory Epithelial Cells by Targeting the Polymeric Immunoglobulin Receptor
}

\author{
Thomas Ferkol, * Charlotte S. Kaetzel, ${ }^{\star}$ and Pamela B. Davis * \\ ${ }^{*}$ Department of Pediatrics at Rainbow Babies and Childrens Hospital, and ${ }^{\ddagger}$ Department of Pathology, \\ Case Western Reserve University School of Medicine, Cleveland, Ohio 44106
}

\begin{abstract}
A system for targeting foreign DNA to epithelial cells in vitro has been developed by exploiting receptor-mediated endocytosis. The polymeric immunoglobulin receptor transports dimeric immunoglobulin $A$ and immunoglobulin $M$ through epithelial cells, including those of the respiratory tract, by binding the immunoglobulins at the basolateral surface and transporting them across the cell. Fab fragments of antibodies directed against the extracellular portion of the receptor, secretory component, are similarly transported. Anti-human secretory component Fab fragments were covalently linked to a polycation, and complexed to various expression plasmids. When bound to an expression plasmid containing the Escherichia coli lacZ gene ligated to the Rous sarcoma virus promoter, the complexes transfected HT29.74 human colon carcinoma cells induced to express polymeric immunoglobulin receptor, but not those lacking the receptor. Primary cultures of human tracheal epithelial cells grown on collagen gels, which induce the expression of polymeric immunoglobulin receptor, were also transfected with the complexes. From 5 to $66 \%$ of the respiratory epithelial cells had $\beta$-galactosidase activity after treatment, comparable to the percentage of cultured human tracheal epithelial cells that express polymeric immunoglobulin receptor $(8-35 \%)$. The addition of excess human secretory component (Fab ligand) to the culture medium at the time of transfection blocked the delivery of DNA. The expression plasmid, either alone, complexed to the polycation, or complexed to a carrier based on an irrelevant Fab fragment, was not effective in transfecting either cell type. This DNA carrier system introduces DNA specifically into epithelial cells that contain pIgR in vitro. (J. Clin. Invest. 1993.92:2394-2400.) Key words: polymeric immunoglobulin receptor - DNA transfection • gene targeting • secretory component $\bullet$ trachea $\bullet$ epithelial cells
\end{abstract}

\section{Introduction}

In cystic fibrosis (CF), ${ }^{1}$ the most common lethal genetic disease of Caucasians, the defective function of the cystic fibrosis transmembrane conductance regulator (CFTR) in airway epithelial cells and submucosal glands results in chronic, suppura-

Address correspondence to Dr. Thomas Ferkol, Pediatric Pulmonology Department, Rainbow Babies and Children's Hospital, Case Western Reserve University, 2074 Abington Road, Cleveland, OH 44106. 1993.

Received for publication 21 January 1993 and in revised form 2 July

J. Clin. Invest.

(c) The American Society for Clinical Investigation, Inc.

$0021-9738 / 93 / 11 / 2394 / 07 \quad \$ 2.00$

Volume 92, November 1993, 2394-2400 tive pulmonary disease, usually leading to death. Because $\mathrm{CF}$ is an autosomal recessive disorder, gene augmentation could theoretically correct the defect provided that methods of delivering normal copies of CFTR to affected cells are safe, efficient, and selective.

Replication deficient, recombinant adenoviruses have been used to deliver genes to respiratory epithelial cells $(1,2)$. Although this method of gene transfer has considerable appeal for its efficiency, adenoviruses may lack sufficient cell selectivity in vivo. The physiologic effects of treatment with adenovirus are unknown. Furthermore, concerns have arisen that the disabled viral vectors might become activated following infection and produce replication-competent virus (3). Adeno-associated virus $(4,5)$ and recombinant retroviruses $(6,7)$ have also been proposed as vectors for introducing genes into the respiratory tract, but both systems have had significant practical limitations (3). Mechanical techniques of gene transfer, like lipofection (8-10), may have substantial cytotoxicity and lack specificity. Receptor-mediated gene transfer, however, affords specificity in the context of a noninfectious vector.

The polymeric immunoglobulin receptor ( $\mathrm{pIgR})$ is expressed only in human mucosal epithelial cells, including airway epithelial cells, submucosal gland cells, and intestinal cells. It is specifically adapted for the internalization of large molecules, including noncovalent complexes of immunoglobulin A (IgA) and antigen, by endocytosis (11-13). This receptor therefore appears to be an ideal candidate for receptor-mediated gene transfer. We tested this hypothesis by examining the ability of pIgR to deliver functional exogenous genes to human intestinal and tracheal epithelial cells that express the receptor.

\section{Methods}

Materials. DNA-modifying enzymes, nucleotides, $\alpha$-nitrophenyl- $\beta$-Dgalactopyranoside (ONPG), and 5-bromo-4-chloro-3-indolyl- $\beta$-D-galactopyranoside (X-gal) were purchased from Boehringer Mannheim Biochemicals (Indianapolis, IN). GeneScreen Plus, $\left[{ }^{14} \mathrm{C}\right]$ chloramphenicol, and $\left[\alpha^{32} \mathrm{P}\right] \mathrm{dCTP}$ were obtained from DuPont-New England Nuclear (Boston, MA). Protein A MAPS agarose columns were purchased from BioRad Laboratories (Richmond, CA). Papain and poly (L-lysine) were obtained from Sigma Chemical Company (St. Louis, $\mathrm{MO}$ ), and $\mathrm{N}$-succinimidyl-3-(2-pyridyldithio)proprionate was purchased from Pierce Chemical Company (Rockford, IL). All media, sera, and antibiotics were obtained from Gibco Laboratories (Grand Island, NY).

Preparation of Fab fragments. Antisera were raised in rabbits against secretory component purified from human colostrum. The an-

1. Abbreviations used in this paper: CF, cystic fibrosis; CFTR, cystic fibrosis transmembrane conductance regulator; ONPG, $o$-nitrophenyl $\beta$-D-galactopyranoside; pIgR, polymeric immunoglobulin receptor; SC, secretory component; SPDP, N-succinimidyl 3-(2-pyridyldithio)proprionate; X-gal, 5 -bromo-4-chloro-3-indolyl- $\beta$-galactopyranoside. 
tibody recognizes purified secretory component (SC), secretory IgA, and the polymeric immunoglobulin receptor, but not dimeric IgA (15). The antibody was isolated using a Protein A MAPS agarose column as described by the manufacturer, and was subjected to cleavage by insoluble papain attached to agarose beads. Briefly, $2 \mathrm{mg}$ of isolated immunoglobulin $\mathrm{G}$ ( $\mathrm{IgG}$ ) was treated with $20 \mu \mathrm{g}$ papain for $12 \mathrm{~h}$ at $37^{\circ} \mathrm{C}$ in the presence of $100 \mathrm{mM}$ sodium acetate, $\mathrm{pH} 5.5,50 \mathrm{mM}$ cysteine, and $1 \mathrm{mM}$ EDTA. The Fab fragment was separated from intact antibody and Fc fragments by Protein A chromatography. An irrelevant Fab was also generated by papain digestion of IgG from preimmune rabbit serum.

Preparation of Fab-polylysine conjugates. The Fab fragment of the anti-pIgR immunoglobulin $\mathrm{G}$ was covalently linked to poly (L-lysine) $\left(M_{\mathrm{r}} 20,000 \mathrm{D}\right)$ using the heterobifunctional crosslinking reagent $\mathrm{N}$ succinimidyl 3-(2-pyridyldithio) proprionate (SPDP). The Fab fragment was incubated with a fifteenfold molar excess of SPDP in $0.1 \mathrm{M}$ PBS, pH 7.5, at $22^{\circ} \mathrm{C}$ for $60 \mathrm{~min}$. After introduction of 2-pyridyl disulfide structures onto the Fab fragment, unreacted SPDP and low molecular weight reaction products were removed by dialysis. The disulfide bridges of the modified Fab fragment were cleaved with $25 \mathrm{mM}$ DTT, pH 4.5. Fifteenfold molar excess of poly (L-lysine) and SPDP was added to the modified Fab fragment, and the reaction was carried out at $22^{\circ} \mathrm{C}$ for $24 \mathrm{~h}$. The conjugate was dialyzed to remove low molecular weight reaction products, and analyzed by separating the resultant proteins on a $0.1 \%$ SDS- $7.5 \%$ polyacrylamide gel electrophoresis. Gels were stained with Coomassie brilliant blue for $2 \mathrm{~h}$, and subsequently destained for $24 \mathrm{~h}$ with a solution containing $30 \%$ methanol and $10 \%$ acetic acid. Analysis of different preparations demonstrated a protein that migrated slowly, corresponding to a protein greater than $200 \mathrm{kD}$ in size (data not shown). This slow migration is most likely due to the high proportion of basic amino acids, i.e., lysine, attached to the Fab fragment. A small fraction of the Fab portion did not bind to the poly ( $\mathrm{L}$-lysine), as evidenced by the presence of a $50-\mathrm{kD}$ protein, the expected size of the fragment.

Reporter genes and plasmid preparation. The plasmids pRSVZ and pRSVCAT, consisting of the Escherichia coli lacZ and chloramphenicol acetyltransferase genes, respectively, ligated to the Rous sarcoma virus long terminal repeat promoter inserted into a modified pBR322 vector, were used as reporter genes. The plasmids were grown in $E$. coli DH $5 \alpha$, extracted, and purified by standard techniques (14). Digestions of the plasmids with restriction endonucleases yielded the appropriate size fragments, and purity was established by $1.0 \%$ agarose gel electrophoresis. The sizes of pRSVZ and pRSVCAT are approximately 5.8 and $5.0 \mathrm{kB}$, respectively. No bacterial genomic DNA was present.

Preparation of Fab-polylysine-DNA complexes. Complexes were formed by combining plasmid DNA with the Fab-polylysine in $3 \mathrm{M}$ $\mathrm{NaCl}$. The charge ratio of the DNA phosphate to lysine was $\sim 1.2: 1$. Samples were incubated for $60 \mathrm{~min}$ at $22^{\circ} \mathrm{C}$, then dialyzed against 0.15 $\mathrm{M} \mathrm{NaCl}$ for $16 \mathrm{~h}$ through membranes with a 3,500-dalton molecular mass limit. On visual inspection, no precipitates were present in the dialysate. The complexes were filtered through a Millipore filter with $0.45 \mu \mathrm{m}$ pore size, and maintained at $4^{\circ} \mathrm{C}$ prior to use.

Determination of optimal conjugate to DNA proportion. To determine the optimal proportion of conjugate to DNA, increasing amounts of the conjugate were added to $10 \mu \mathrm{g}$ of pRSVZ, producing 1:4, 1:8, 1:16, and 1:32 DNA to carrier ( Fab) molar ratios. Samples were incubated as described above, and dialyzed overnight against $0.15 \mathrm{M} \mathrm{NaCl}$. The complexes were filtered before use. Samples containing equal amounts of DNA $(1 \mu \mathrm{g})$ were separated by $1.0 \%$ agarose gel electrophoresis and stained with ethidium bromide. The plasmid DNA was transferred onto a nitrocellulose filter and analyzed by Southern blot hybridization, using the 2.3-kB EcoRI fragment of pRSVZ as a DNA probe. The probe was labeled using $\left[\alpha^{32} \mathrm{P}\right] \mathrm{dCTP}$, by the method of random oligo-priming as described by the manufacturer. The specific activity was $10^{9} \mathrm{cpm} / \mu \mathrm{g}$ DNA.

Cells and cell culture. A subclone of human clonic carcinoma HT29 cells (HT29.74) were cultured as previously described (15), and maintained in RPMI Media 1640. Human tracheal epithelial cells were harvested from necropsy specimens less than $24 \mathrm{~h}$ postmortem using a modification of the procedure described by Wu (16) and cultured (11) as previously described. Cells were grown on collagen gel matrices (11, 17) or on uncoated plates. Transfections were planned to be performed when the cells were $\sim 50 \%$ confluent. However, because of variations in cell growth the actual transfections were done when cells were 50 to $95 \%$ confluent. Viability of cells was determined by trypan blue exclusion.

DNA delivery to cells. $4 \mathrm{~d}$ before transfection, the HT29.74 cells were washed twice with PBS, pH 7.4. Half of the cells were returned to RPMI Media 1640, and the remaining half were grown in Leibovitz L15 Media, a glucose-deficient culture medium. Human gamma interferon, $100 \mathrm{U} / \mathrm{ml}$, was added to half of the cells grown in glucose-deficient media $2 \mathrm{~d}$ before transfection. Transfer of HT29.74 cells to glucose-free media increases expression of pIgR (15), as does treatment with human gamma interferon (18-21). Cell density was approximately $5 \times 10^{4}$ cells per plate at the time of transfection. Growth medium was changed and the cells were washed with PBS. Solutions containing Fab-polylysine-DNA complex ( 2.5 pmol DNA noncovalently bound to $10,20,40$, or $80 \mathrm{pmol} \mathrm{Fab})$, polylysine-DNA complex $(2.5$ pmol DNA complexed with $1.2 \mathrm{nmol}$ polylysine), Fab-polylysine ( 80 pmol ) alone, or $2.5 \mathrm{pmol}(20 \mu \mathrm{g})$ DNA alone, were added to individual plates. Each sample was filtered prior to transfection of cells. After the cells were incubated for $48 \mathrm{~h}$ at $37^{\circ} \mathrm{C}$, either in vitro or in situ $\beta$-galactosidase assays were performed.

When primary cultures of human tracheal epithelial cells were $50 \%$ confluent, cells were washed once with PBS, $\mathrm{pH} 7.4$, and the media was changed immediately before transfection. The conjugate-DNA complex, containing $10 \mu \mathrm{g}(1.3 \mathrm{pmol})$ plasmid, was applied and permitted to remain on the cells for $48 \mathrm{~h}$. The cells were then either harvested for protein extraction or fixed for in situ $\beta$-galactosidase assays.

Assays for $\beta$-galactosidase activity. The cells were washed in cold phosphate buffer once, then scraped from the plate in a solution consisting of $10 \mathrm{mM}$ Tris, $\mathrm{pH} 7.5,150 \mathrm{mM} \mathrm{NaCl}$, and $1 \mathrm{mM}$ EDTA. Centrifuged at $10,000 \mathrm{rpm}$ for 1 minute, the cell pellets were resus-

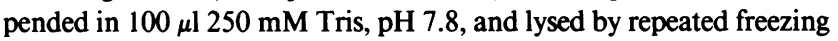
and thawing. Aliquots of the supernatant were assayed for protein content, and samples of supernatants containing equal amounts of protein were incubated at $37^{\circ} \mathrm{C}$ for $12 \mathrm{~h}$ with $520 \mathrm{mg}$ ONPG as described (22). The optical density of the samples was measured at $420 \mathrm{~nm}$.

Individual cells expressing $\beta$-galactosidase were also identified following incubation with X-gal as described previously (22). Briefly, the cells were fixed with a solution of $1 \%$ glutaraldehyde in PBS for $15 \mathrm{~min}$, and then incubated with a solution containing $0.5 \% \mathrm{X}$-gal for 12 to $16 \mathrm{~h}$ at either 22 or $37^{\circ} \mathrm{C}$. Blue colored cells were identified by phase-contrast light microscopy. A minimum of 100 cells were counted to determine the percentage of cells expressing $\beta$-galactosidase.

Assay for chloramphenicol acetyltransferase. Human tracheal epi-

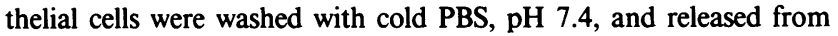
collagen gels by treatment with collagenase. Centrifuged at $12,000 \mathrm{rpm}$ for $2 \mathrm{~min}$ at $4^{\circ} \mathrm{C}$, the pellet was resuspended in $200 \mu \mathrm{l}$ of $250 \mathrm{mM}$ Tris $\mathrm{Cl}, \mathrm{pH} \mathrm{7.8}$, and sonicated for $1 \mathrm{~min}$. The samples were centrifuged at $12,000 \mathrm{rpm}$ for $10 \mathrm{~min}$ at $4^{\circ} \mathrm{C}$. The supernatants were analyzed for protein content, and aliquots were incubated at $37^{\circ} \mathrm{C}$ with $\left[{ }^{14} \mathrm{C}\right]-$ chloramphenicol and acetyl coenzyme A in $250 \mathrm{mM}$ Tris $\mathrm{Cl}$, pH 7.5. The reaction products were extracted with ethyl acetate, and applied to filter paper. TLC was performed, and developed using 19:1 mixture of chloroform and pethanol. After air drying, the plates were exposed to a Phosphor Screen (Molecular Dynamics), and radioactivity of the acetylated chloramphenicol spots was measured by PhosphoImager (Molecular Dynamics). The chloramphenicol acetyltransferase activity of each sample was adjusted for the protein content of the cell extract.

Immunohistochemical staining of cells for pIgR. The expression of plgR in human tracheal epithelial cells transfected with the plasmid pRSVZ was determined by indirect immunofluorescence. After in situ $\beta$-galactosidase staining, the cells were fixed with a solution containing $2 \%$ paraformaldehyde, $10 \mathrm{mM} \mathrm{NaIO}_{4}, 37 \mathrm{mM} \mathrm{Na}_{2} \mathrm{HPO}_{4}$, and $75 \mathrm{mM}$ lysine, $\mathrm{pH} 6.2$, for $2 \mathrm{~h}$. The cells were made permeable by treatment 
with PBS containing $0.1 \%$ (wt/ vol) ovalbumin and $0.05 \%$ saponin, then incubated sequentially with rabbit anti-human SC and fluorescein-conjugated goat anti-rabbit IgG. Both antibodies were diluted $1: 100$ in PBS containing $0.1 \%$ (wt/ vol) ovalbumin and $0.05 \%$ saponin. Between each incubation, the cells were washed three times with PBS containing $0.1 \%$ (wt $/ \mathrm{vol}$ ) ovalbumin. The stained cells were examined by fluorescent microscopy.

Statistical analysis. Data are expressed as means \pm SEM, and evaluated using an analysis of variance using the Student-Newman-Keuls (SNK) test (23).

\section{Results}

The Fab-polylysine carrier and DNA complex. A DNA carrier was constructed by coupling poly (L-lysine) to the Fab fragment of IgG directed against human secretory component using $n$-succinimidyl 3-(2-pyridyldithio) proprionate (SPDP) as a heterobifunctional reagent. The ability of the Fab-polylysine conjugate to form effective, stable complexes with plasmid DNA was examined by a gel retardation assay. Fig. $1 a$ illustrates that increasing the proportion of the Fab-polylysine conjugate in plasmid samples increased retardation of DNA migration in an agarose gel. Full retardation was achieved by a DNA to carrier (Fab) molar ratio of 1:16. Ethidium bromide staining of plasmid was also reduced as higher ratios of conjugate to DNA were used, suggesting that increased concentrations of the carrier may condense the plasmid into a toroid form (24).

Transfection of HT29.74 cells using the Fab-polylysine carrier. Using an expression plasmid encoding the $E$. coli lacZ gene as a reporter gene, complexes of the plasmid and Fabpolylysine conjugate in various molar ratios were applied to human intestinal HT29.74 cells, which had been grown in glucose-free media and treated with human IFN $\alpha$ to enhance expression of pIgR. After 48-, 96-, and 120-h incubations, cell extracts were prepared and analyzed for $\beta$-galactosidase activity (Fig. $1 \mathrm{~b}$ ). Expression occurred $48 \mathrm{~h}$ after transfection, when the plasmid and carrier were combined in 1:16 molar ratio. Optimal transfection was achieved with this DNA:carrier ratio at $96 \mathrm{~h}$. Expression had vanished by $120 \mathrm{~h}$ after transfection. The carrier delivered DNA to $5-10 \%$ of HT29.74 cells, which had been grown in glucose-free media and treated with human IFN $\alpha$, as compared to $<3 \%$ of cells grown in glucose (data not shown). Rare cells treated with either the conjugate or DNA alone were also blue stained, most likely due to an endogenous $\beta$-galactosidase. Nevertheless, the percentage of blue stained cells in the controls was significantly less than that in the transfected dishes.

Transfection of human tracheal epithelial cells. We have previously shown that human tracheal epithelial cells grown on plastic down-regulate the expression of pIgR, whereas cells grown on collagen gels maintain production (9). To estimate the proportion of cells grown on collagen that express the receptor, two strategies were used. First, after demonstrating that collagenase does not affect the pIgR immunoreactivity (9), the cells were released from the collagen support enzymatically, stained with antibody directed against the receptor and antirabbit FITC, and counted in a fluorescence activated cell sorter $\left(\right.$ FACS $\left.^{\circledR}\right)$. Alternatively, the cells were stained in situ in the same manner and counted on the plate. These two techniques indicated that the expression of the pIgR in primary tracheal epithelial cells is variable, ranging from 8 to $35 \%$ of cells in
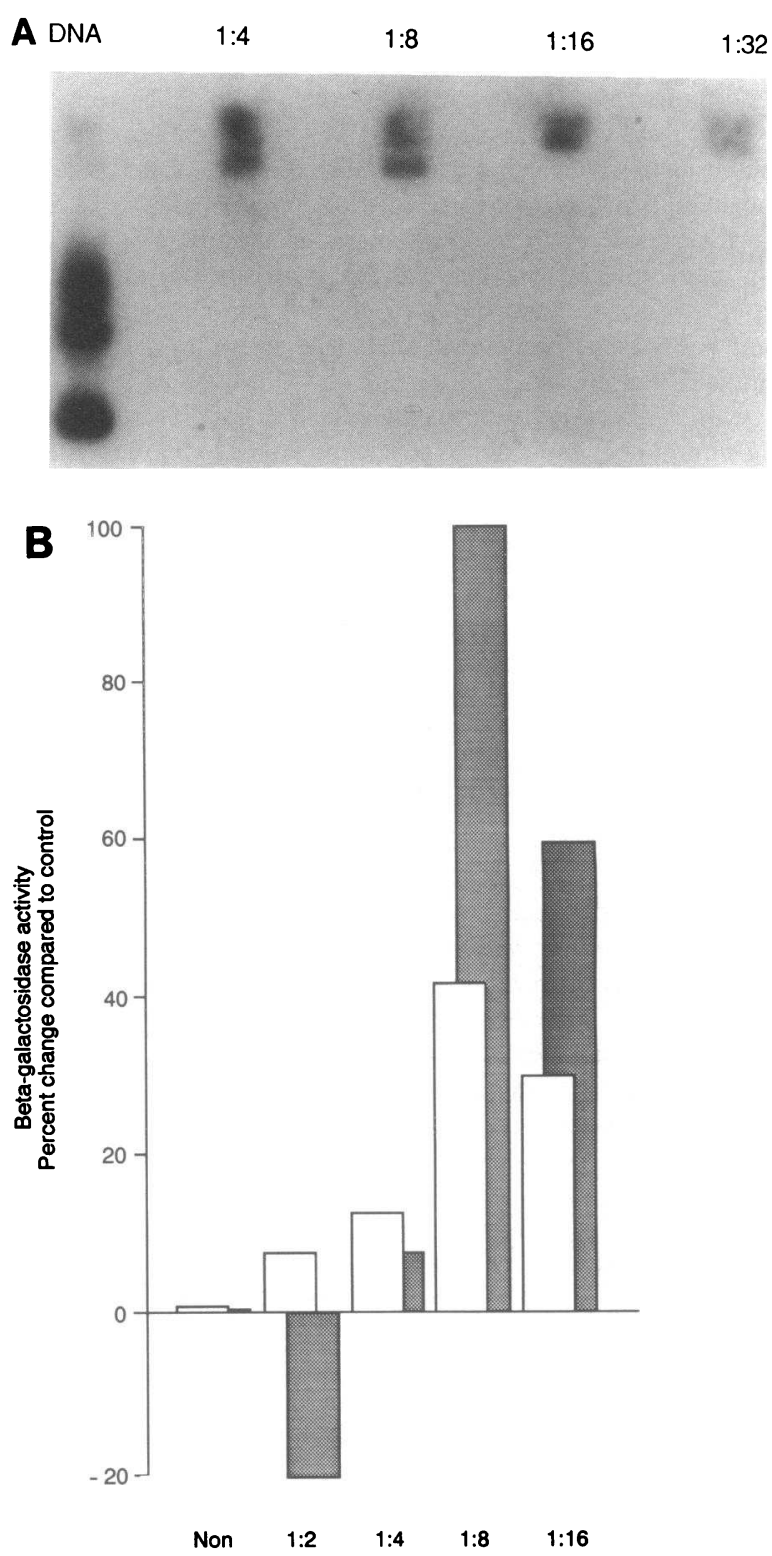

Figure 1. (A) Gel shift of plasmid DNA with the Fab-polylysine carrier. The noncovalent binding of DNA to the carrier was established by gel mobility shift assay with pRSVZ. Increasing concentrations of the Fab-polylysine conjugate were added to DNA to form complexes yielding DNA: carrier ( $\mathrm{Fab}$ ) molar ratios of 0 (DNA alone), $1: 4,1: 8,1: 16$, and 1:32. After dialysis and filtration of the complexes, samples containing $1 \mu \mathrm{g}$ DNA were examined by $1.0 \%$ agarose gel electrophoresis. DNA was transferred to a nitrocellulose filter and analyzed by Southern blot hybridization, using a radiolabeled probe specific for pRSVZ. Lane 1: DNA alone; lanes 2-5: complexes at indicated molar ratios. $(B)$ Gene transfection of HT29.74 human colonic carcinoma cells using the Fab-polylysine carrier. HT29.74 cells were grown in Leibovitz L15 culture media and treated with $100 \mathrm{U} /$ ml human IFN $\alpha 2 \mathrm{~d}$ before transfection with $10 \mu \mathrm{g}$ of pRSVZ complexed to the Fab-polylysine carrier using various molar ratios. Transfections were performed in duplicate. Cells were then incubated with the complexes at $37^{\circ} \mathrm{C}$ for 48 and $96 \mathrm{~h}$, harvested, and lysed. Protein extracts were pooled and analyzed for $\beta$-galactosidase activity using an in vitro assay. The relative activity of cell extracts is expressed as percent change compared to nontransfected controls (Non). Column 1 represents $\beta$-galactosidase activity in nontransfected control cells, whereas columns 2-6 show the activity in cell extracts 48 (open bars) and $96 \mathrm{~h}$ ( solid bars) after transfection with complexes at 1:2, 1:4, 1:8, and 1:16 DNA-carrier molar ratios. 
culture. $\mathrm{FACS}^{\circledast}$ analysis demonstrated a mean of $21.6 \pm 5.9 \%(n$ $=4)$ pIgR positive cells.

Primary cultures of human tracheal epithelial cells grown on collagen gels were transfected using the Fab-polylysine carrier. Table I lists the percent of cells positive for $\beta$-galactosidase under different conditions for nine separate human tracheal epithelial cell preparations. In all cases, a significantly greater number of cells exposed to the complex expressed the reporter gene than controls. The proportion of transfected cells varied considerably, from 5 to $66 \%$ of cells examined. DNA carriers synthesized from nonspecific, preimmune Fab fragment were ineffective in transfecting human tracheal epithelial cells. The number of blue stained cells using such irrelevant carrier was similar to nontransfected controls. Fig. 2 demonstrates the transfected cells and individual controls. In addition, the carrier-DNA complex was nontoxic to cells, based on trypan blue staining. The percentage of cells viable after treatment was not significantly different than controls (mean 92.5 vs. $87.7 \%$ ). Primary cultures of tracheal epithelial cells were analyzed for the presence of pIgR by in situ immunohistochemical staining after transfection. Several cells in each microscopic field did not express pIgR based on immunofluorescent staining. Most of cells that expressed pIgR were transfected using the Fabpolylysine carrier, as exhibited by the presence of $\beta$-galactosidase activity in these cells (Fig. 2). Cells that did not express pIgR were not transfected.

We compared tracheal epithelial cells grown on plastic to cells grown on collagen gels in two separate experiments. In both instances, the percentage of blue stained cells grown on plastic was comparable to nontransfected controls (mean $2.5 \%$ ), whereas a mean of $6 \%$ of the cells maintained on collagen gels were positive in this particular experiment (data not shown). Treatment of the complexes with DTT, which cleaves the crosslinking, disulfide bonds of the Fab-polylysine carrier, completely eliminated uptake and expression of the reporter gene. Addition of a fourfold molar excess of dimeric IgA over complex to the culture media failed to reduce uptake by competing for available pIgR. No significant change in the proportion of cells expressing the reporter gene was noted (Table I). However, incubation with a fourfold molar excess of secretory component, the soluble extracellular domain of pIgR, which reacts with the anti-pIgR Fab fragment, completely inhibited the uptake and expression of the reporter gene (Table I).

$\beta$-galactosidase assays demonstrated a twofold excess of ac-

Table I. Transfection of Human Tracheal Epithelial Cells Using the Fab-polylysine DNA Complex

\begin{tabular}{lccc}
\hline \multicolumn{1}{c}{ Condition } & $N$ & Positive cells & Range \\
\hline & & $\%$ & \\
Nontransfected & 9 & $3.8 \pm 0.9$ & $1-8$ \\
Complex & 9 & $18.0 \pm 6.2^{*}$ & $5-66$ \\
Complex and dIgA & 6 & $12.5 \pm 2.4^{*}$ & $5-20$ \\
Complex and SC & 6 & $4.3 \pm 2.0^{\ddagger}$ & $0-12$
\end{tabular}

Values represent the percent of cells expressing $\beta$-galactosidase (mean \pm standard error of the mean). * Significant difference compared to nontransfected control, $P<0.05$. ${ }^{\ddagger}$ Significant difference compared to cells transfected with complex alone, $P<0.05$. No difference compared to nontransfected control. tivity over background in transfected human tracheal epithelial cells. This was supported by results from chloramphenicol acetyltransferase (CAT) assays. Complexes of the Fab-polylysine carrier and the expression plasmid pRSVCAT were applied to cells, and activity was measured $48 \mathrm{~h}$ after transfection. A threefold increase in chloramphenicol acetyltransferase activity in transfected cells was present $(P<0.01)$, whereas mock transfected cells did not express activity significantly different than nontransfected controls (Fig. 3).

\section{Discussion}

Expression plasmids noncovalently bound to the Fab fragment of antibody directed against the polymeric immunoglobulin receptor ( $\mathrm{pIgR}$ ) can be introduced efficiently into cells that express the receptor. Delivery is specific for cells that express pIgR, since human tracheal epithelial cells grown on plastic, a condition that down-regulates the expression of the receptor, fail to express the reporter gene whereas cells from the same trachea maintained on collagen gels can be transfected. The transfection of HT29.74 cells was also dependent on the level of expression of $\mathrm{pIgR}$, since cells grown in conditions that upregulate the receptor express the reporter gene more than cells grown in undifferentiating conditions. Delivery of DNA is inhibited by excess secretory component in the medium, which presumably occupies the recognition site on the Fab fragment, preventing its interaction with the receptor. However, competition for the pIgR with dimeric IgA in a fourfold molar excess failed to block the delivery of the complex, perhaps indicating that the binding site(s) on the pIgR for dimeric IgA and antiSC do not overlap. Alternatively, the natural ligand may not compete effectively with the anti-SC for the receptor, or the receptor may be present in excess. Uptake is not due to a nonspecific increase in pinocytosis secondary to the presence of the Fab fragment in the culture medium, for the addition of Fab fragments with uncomplexed DNA or the carrier-DNA complex after dissociation with DTT does not result in an increase in reporter gene expression. Moreover, the use of complexes with Fab fragments from irrelevant antibodies did not permit the uptake and expression of the reporter gene. Thus, the uptake and expression of the reporter gene is mediated by the specific interaction of the complex with pIgR.

The specificity of gene transfer in vitro for cells that bear the pIgR as well as the success of gene transfer in the presence of the natural ligand for the receptor permits speculation as to whether this strategy might be useful in delivering genes into the defective cells in the bronchi and bronchioles of patients with cystic fibrosis. In humans, the pIgR is expressed in airway epithelial cells that reach the luminal surface and in cells of the submucosal glands, especially serous cells (11). This distribution conforms to that of CFTR in the airway. The pIgR is expressed in human fetuses from the 16th gestational wk (25), secretory component has been found in tracheal aspirates from premature neonates (26), and patients with cystic fibrosis express this protein at normal or, in some instances, at elevated levels (27). Furthermore, the anti-SC provides greater specificity for the targeted cells than the natural ligand dimeric $\operatorname{IgA}$, which can bind to alternative receptors (e.g., Fc receptors) on other cell types. Specific targeting of these cells may be of importance for gene therapy of cystic fibrosis, because the indiscriminate insertion of cAMP-regulated chloride channels into many cell types may be undesirable. In addition, the expense of 
A
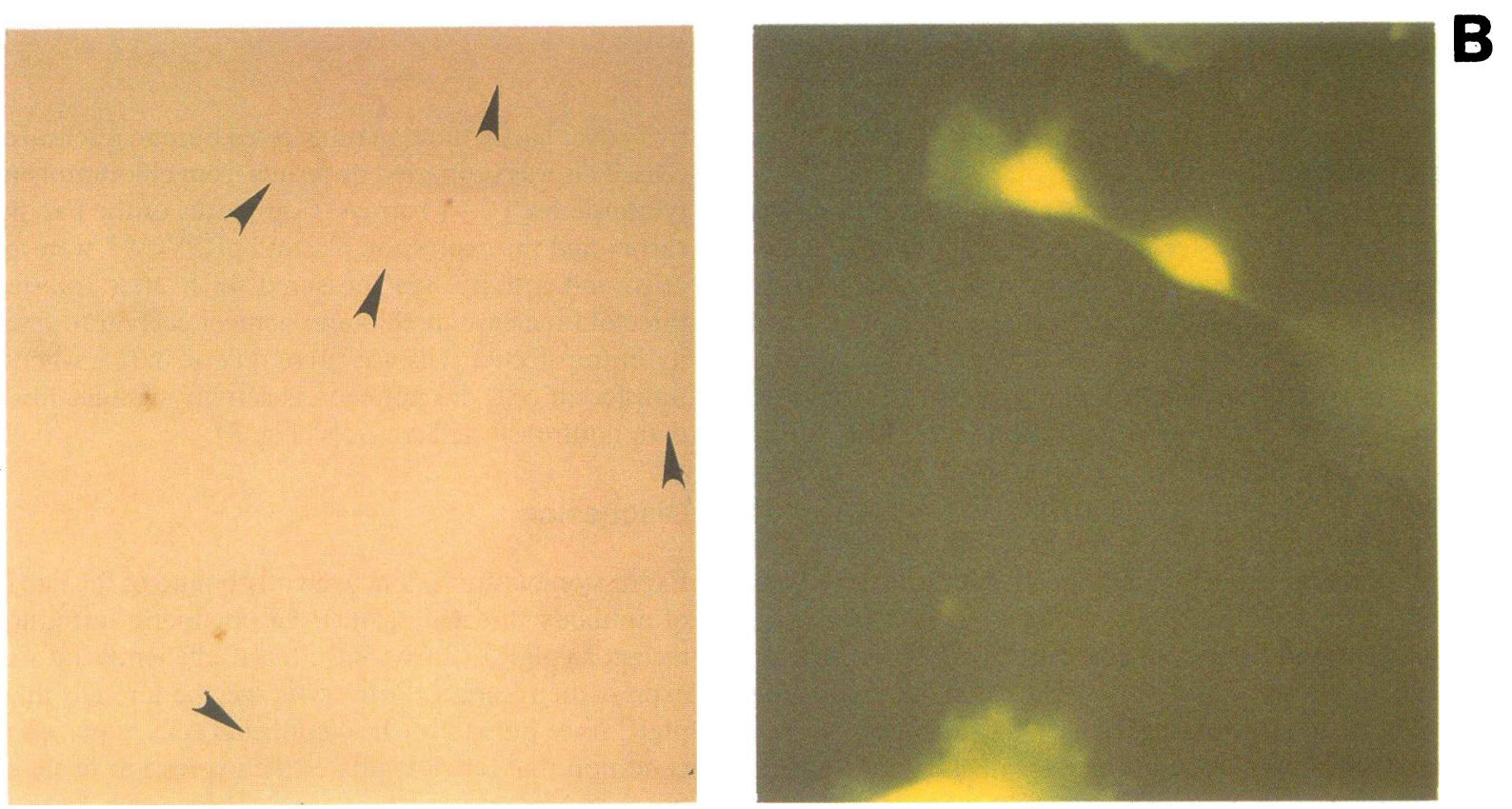

C
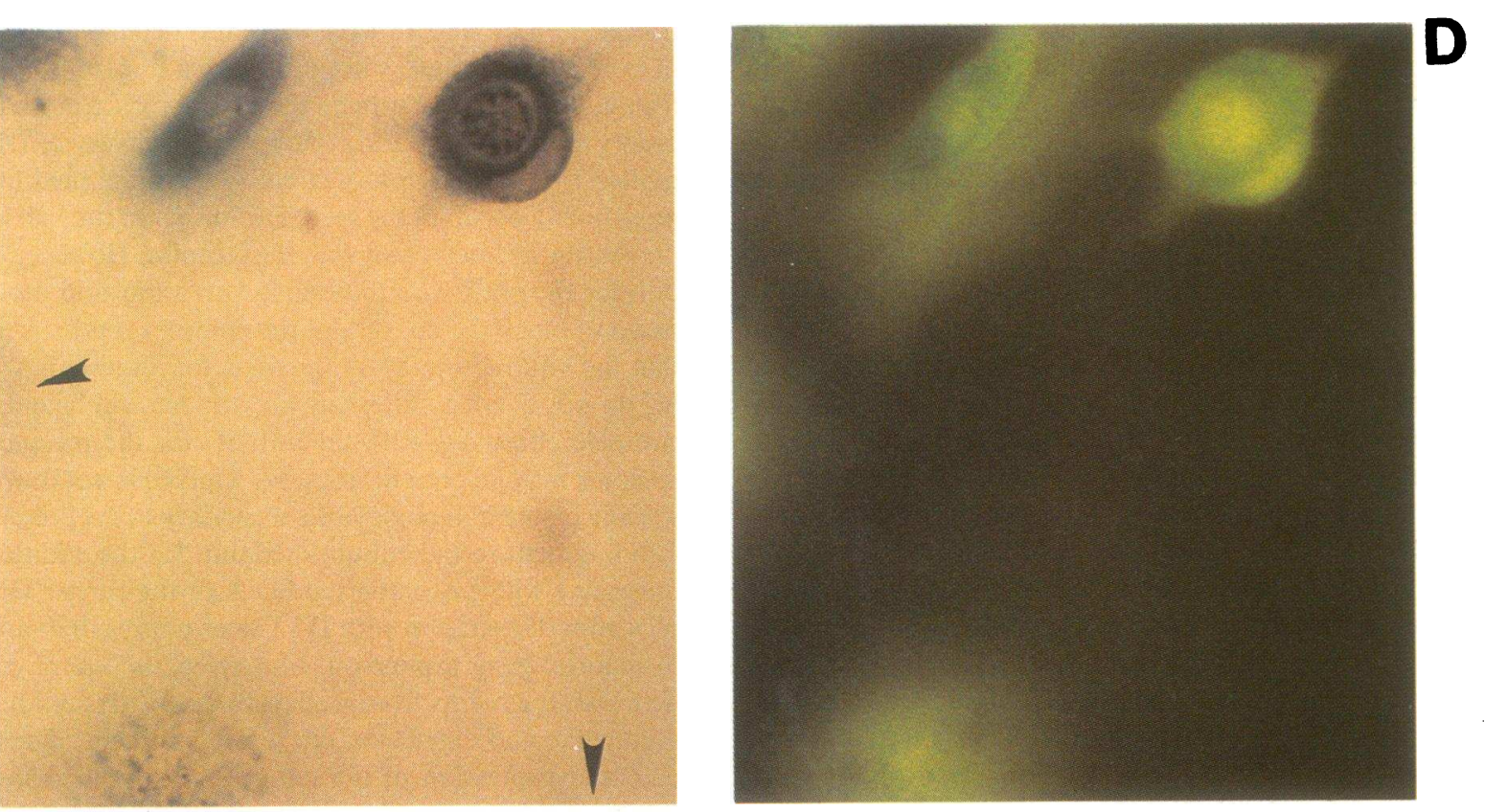

E
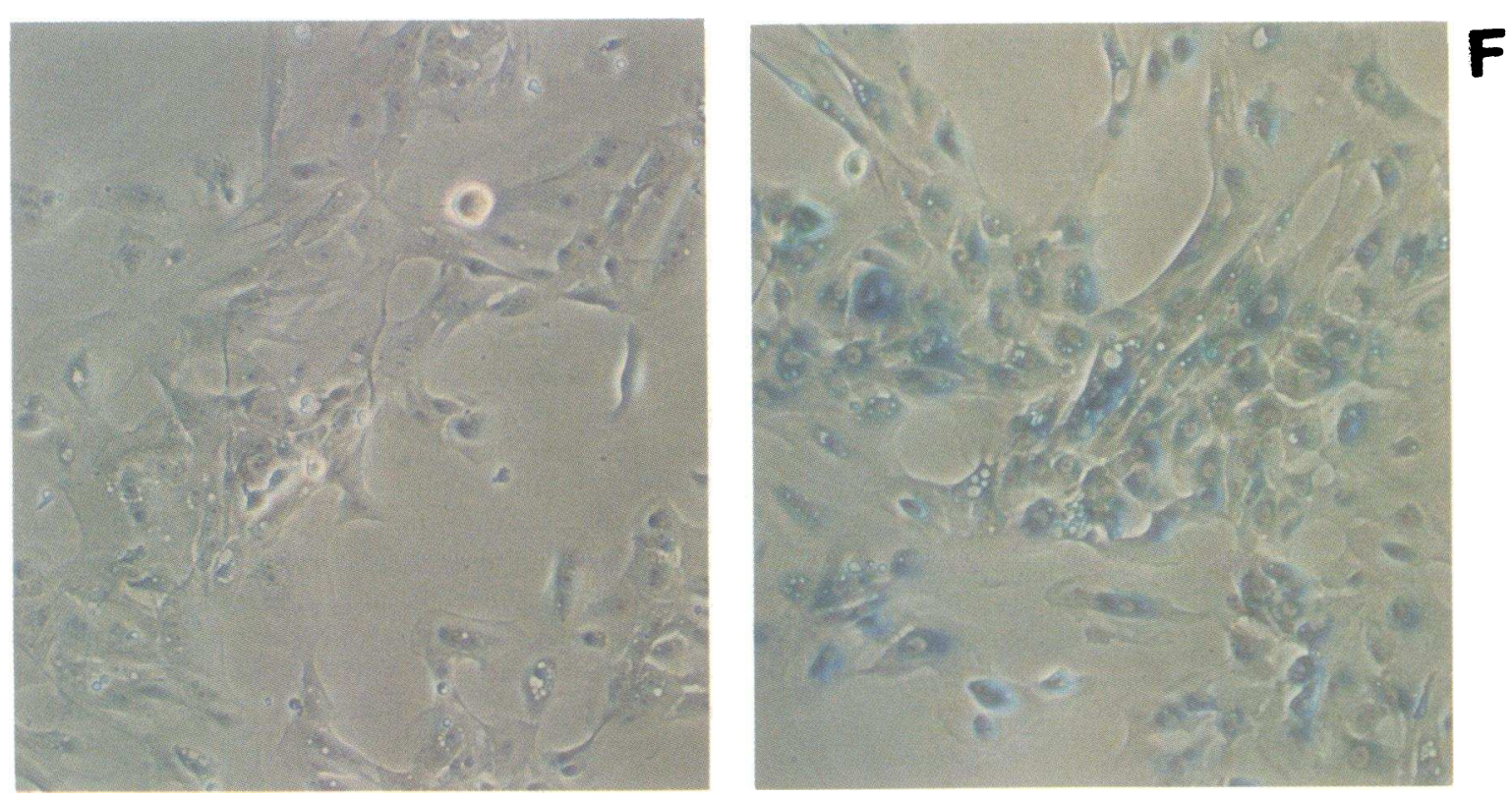


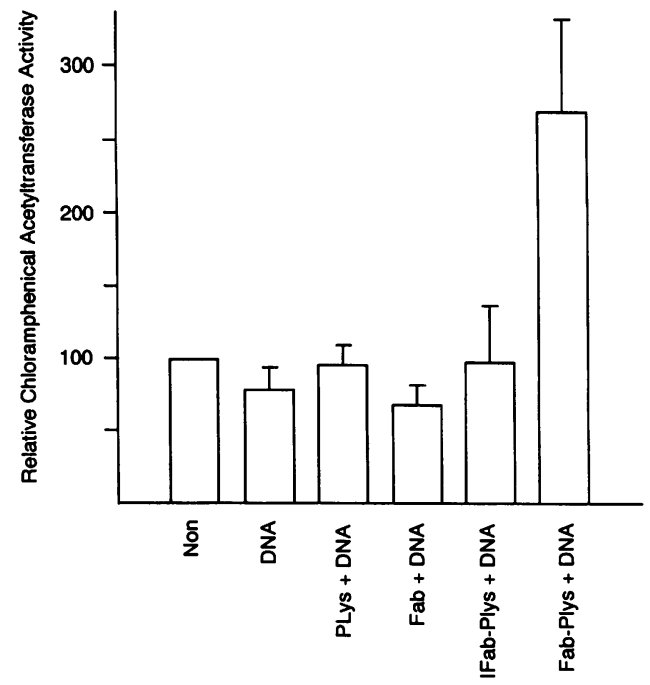

Figure 3. Gene transfection in human tracheal epithelial cells. Primary human tracheal epithelial cells grown on a collagen gel matrix in $60-\mathrm{mm}$ diameter plates were treated with DNA-Fab-polylysine complexes, employing pRSVCAT as an expression plasmid. Transfections were performed in duplicate. Cells were harvested after 48 $\mathrm{h}$, and their protein extracts pooled. The cell extracts were analyzed for chloramphenicol acetyltransferase activity by quantitating the amount of acetylated chloramphenicol using TLC as described in Methods. The chloramphenicol acetyltransferase activity of each sample was corrected for the protein concentration of each extract. The individual columns represent the activity relative to that detected in nontransfected control cells (Non), and the number of pooled samples analyzed is indicated at the base of each column. Relative chloramphenicol acetyltransferase activity in cells treated with DNA alone ( $D N A)$, DNA complexed with polylysine (PLys + DNA; ), DNA combined with anti-SC Fab $(F a b+D N A)$, DNA complexed to an irrelevant Fab-based carrier (IFab-PLys + DNA), and DNA complexed to the carrier (Fab-PLys $+D N A)$ are shown.

producing large quantities of DNA and vector, in excess of what is necessary for the physiologic correction of the defect in target cells, could make nonselective gene transfer impractical. Thus, targeting this receptor may be a potential method of introducing normal copies of the CFTR gene into respiratory cells in patients with cystic fibrosis. However, because the pIgR is asymmetrically distributed, predominantly on the basolateral surface of epithelial cells, the complex would need to be delivered via injection into the systemic circulation. This route may not be practical due to the endothelial cell barriers to egress of the complex from the blood to the underlying tissue.

Even if the proper cells could be targeted, the extent and level of expression of the transgene would need to be sufficient for the treatment of cystic fibrosis. The proportion of cells that must undergo genetic correction to achieve electrophysiologic correction of human tracheal epithelial cells in monolayer cul- ture has been estimated to be as low as $6 \%$ (28), a level achievable in vitro by this method of gene transfer. A variable percentage of primary human tracheal epithelial cells in culture were transfected via the pIgR. The sources of variability of this gene transfer system are not entirely clear at the present time, but could reside either in the complex or with the target cells. Although the complexes were produced using the same procedure each time, the amount of free carrier or unbound plasmid present in the sample could vary and contribute to the differences in uptake. However, it seems more likely that the differences in pIgR expression in the cultured cells will account for most of the observed variation. The proportion of human tracheal epithelial cells in culture that express pIgR, which is detectable by immunofluorescence, ranges from 8-35\%, compared to 5-66\% of the cells that express the reporter gene delivered by the carrier, so it may be that the majority of cells in culture that actually express pIgR are transfected. In fact, the expression of the reporter gene was co-localized to cells that expressed the pIgR, as identified by immunohistochemical means. Consequently, this technique could potentially be useful in vivo, where the majority of the airway epithelial cells and serous cells of the submucosal glands express pIgR $(11,27,29)$.

The level of expression of the reporter genes in the system in vitro was low. In order to detect the blue color characteristic of $\beta$-galactosidase in transfected cells, the preparations required prolonged incubations with the reagents, and even so, the staining was not intense. Quantitative in vitro enzymatic assays showed only low levels of $\beta$-galactosidase or chloramphenicol acetyltransferase expression. Expression of genes introduced by receptor-mediated mechanisms may be limited by the trapping and degradation of the complex in endosomal compartments $(30,31)$, or, in the case of pIgR, the complex may undergo transcytosis and be discharged from the cell complexed with secretory component. However, the level of expression necessary for gene transfer to be therapeutic will greatly depend on the disorder being treated. For example, the level of CFTR expression required in airway cells for functional correction of the defect may be quite low. The CFTR protein is difficult to detect histochemically (32), and mRNA transcripts are not abundant in airway cells (33). Individuals who are heterozygous for CF are phenotypically normal and their pulmonary function is unimpaired, thus half the normal complement of CFTR is adequate. Moreover, phenotypically normal humans have been identified who express an alternatively spliced, inactive form that accounts for as high as $92 \%$ of the total CFTR mRNA (34). Therefore, low levels of expression of normal CFTR directed by a transferred exogenous gene may be sufficient for functional correction of the genetic defect.

In summary, the spatial distribution of the pIgR and specificity of gene delivery using the described method may be favorable for gene therapy. The level of transgene expression.

Figure 2. Photomicrographs of human tracheal epithelial cells transfected with pRSVZ using the Fab-polylysine carrier. $10 \mu \mathrm{g}$ of pRSVZ were complexed to the carrier and applied to primary human tracheal epithelial cells grown on a collagen gel matrix. After $48 \mathrm{~h}$, the cells were stained with a solution containing $0.5 \% \mathrm{X}$-gal as described in Methods. In addition, the cells were also analyzed for the presence of the plgR by indirect immunofluorescence. Unstained cells are indicated by arrows. Photomicrographs $(A)$ phase contrast view of nontransfected human tracheal epithelial cells after X-gal staining $(\times 62.5) ;(B)$ view of nontransfected human tracheal epithelial cells after indirect immunofluorescence staining; $(C)$ phase contrast view of transfected human tracheal epithelial cells after X-gal staining $(\times 125) ;(D)$ view of transfected human tracheal epithelial cells after indirect immunofluorescence staining; $(E)$ phase contrast view of nontransfected human tracheal epithelial cells at a lower magnification $(\times 25)$ after $X$-gal staining; $(F)$ phase contrast view of transfected human tracheal epithelial cells after $X$-gal staining. 
achieved by this system may also be sufficient for the correction of the CF defect. However, access to the receptor on the basolateral surface of respiratory epithelial cells in vivo may pose formidable problems in developing of this technique for practical use. The use of antibodies as the ligand for receptor mediated gene transfer has been successful in the case of pIgR, and may be applicable to other receptors that undergo internalization. Antibodies, or their Fab fragments, may enhance specificity, since naturally occurring ligands may interact with multiple receptors. In some instances, the natural ligand may be unsuitable for conjugation to a polycation like poly (L-lysine), whereas antibodies can be used for this purpose. Even if the target receptor has not been purified, thus precluding the production of specific antibodies against it, antiidiotype antibodies could be constructed to mimic the structure of the natural ligand. Because internalization of surface receptors appears to be a ubiquitous regulatory mechanism or cellular response, many classes of receptors could potentially be used as a "Trojan horse" to introduce the gene of interest into the cell.

\section{Acknowledgments}

The authors wish to thank Richard Hanson for the critical reading of the manuscript, and Aura Perez for her assistance with the photomicrography. We would also like to thank Yoshie Hervey, Teiko Kimura, Frank Mularo, and Cathy Silski for providing their expert technical support.

This study was supported by National Institutes of Health grants DK27651 and DK43999, and C. S. Kaetzel was supported by grants CA51998 and AI26449 from the National Institutes of Health. T. Ferkol was supported in part by the Cystic Fibrosis Foundation Research Development Program Grant LeRoy Matthews Physician-Scientist Award.

\section{References}

1. Rosenfeld, M. A., K. Yoshimura, B. C. Trapnell, K. Yoneyama, E. R. Rosenthal, W. Dalemans, M. Fukayama, J. Bargon, L. E. Stier, L. Stratford-Perricaudet, et al. 1992. Expression of the cystic fibrosis transmembrane conductance regulator gene to the airway epithelium. Cell. 68:143-155.

2. Rosenfeld, M. A., K. Yoshimura, L. E. Stier, B. C. Trapnell, L. StratfordPerricaudet, M. Perricaudet, W. Dalemans, S. Jallot, A. Mecemir, A. Pavirani, et al. 1991. Adenovirus-mediated transfer of a recombinant alpha-1-antitrypsin gene to the lung epithelium in vivo. Science (Wash. DC). 252:431-434.

3. Collins, F. S. 1991. Cystic fibrosis: molecular biology and theraputic implications. Science (Wash. DC). 256:774-779.

4. Flotte, T. R., R. Solow, R. A. Owens, S. Afione, P. L. Zeitlin, and B. J. Carter. 1991. Gene expression from adeno-associated virus vectors in airway epithelial cells. Am. J. Respir. Cell Mol. Biol. 7:349-356.

5. Flotte, T., S. Afione, R. Solow, and B. Carter. 1992. Expression of CFTR from AAV vectors. Pediatr. Pulmonol. 8(Suppl.):237 (Abstr.).

6. Drumm, M. L., H. A. Pope, W. H. Cliff, J. M. Rommens, S. A. Marvin, L.-C. Tsui, F. S. Collins, R. A. Frizzell, and J. M. Wilson. 1990. Correction of the cystic fibrosis defect in vitro by retrovirus-mediated gene transfer. Cell. 62:12271233.

7. Olsen, J. C., L. G. Johnson, M. L. Wong-Sun, K. L. Moore, R. Swanstrom, and R. C. Boucher. 1992. Long-term expression of a retrovirus-transduced reporter gene in cystic fibrosis airway cells. Pediatr. Pulmonol. 8(Suppl.):261 (Abstr.).

8. Hazinski, T. A., P. A. Ladd, and C. A. DeMatteo. 1991. Localization and induced expression of fusion genes in the rat lung. Am. J. Respir. Cell Mol. Biol. 4:206-209.

9. Huang, L. 1991. Targeted delivery of DNA by immunoliposomes and polymers. Pediatr. Pulmonol. 6(Suppl.):189 (Abstr.).

10. Bout, A., D. Valerio, and B. J. Scholte. 1991. In vivo gene transfer in mouse lung. Pediatr. Pulmonol. 6(Suppl.):246 (Abstr.).

11. Fiedler, M. A., C. S. Kaetzel, and P. B. Davis. 1991. Sustained production of secretory component by primary tracheal epithelial cells in primary culture. Am. J. Physiol. (Lung Cell. Mol. Physiol.) 261:L255-261.
12. Musil, L. S., and J. P. Baezinger. 1987. Cleavage of membrane secretory component to soluble secretory component occurs on the cell surface of rat hepatocyte monolayers. J. Cell. Biol. 104:1725-1733.

13. Kaetzel, C. S., J. K. Robinson, K. R. Chintalacharuvu, J.-P. Vaerman, and M. E. Lamm. 1991. The polymeric immunoglobulin receptor (secretory component) mediates transport of immune complexes across epithelial cells: a local defense function for IgA. Proc. Natl. Acad. Sci. USA. 88:8796-8800.

14. Maniatis, T., E. F. Frisch, and J. Stambrook. 1989. Molecular Cloning: A Laboratory Manual. Cold Spring Harbor Laboratory, Cold Spring Harbor, New York.

15. Chintalacharuvu, K. R., J. F. Piskurich, M. E. Lamm, and C. S. Kaetzel. 1991. Cell polarity regulates the release of secretory component, the epithelial receptor for polymeric immunoglobulins, from the surface of HT-29 colon carcinoma cells. J. Cell. Physiol. 148:35-47.

16. Wu, R., and D. Smith. 1982. Continuous multiplication of rabbit epithelial cells in defined hormone supplemented media. In Vitro. 18:800-812.

17. Infeld, M. D., J. A. Brennan, and P. B. Davis. 1992. Human tracheobronchial epithelial cells direct migration of lung fibroblasts in three-dimensional collagen gels. Am. J. Physiol. (Lung Cell. Mol. Physiol.) 262:L535-541.

18. Piskurich, J. F., J. A. France, C. M. Tamer, C. A. Willmer, C. S. Kaetzel, and D. M. Kaetzel. 1993. Interferon- $\gamma$ induces polymeric immunoglobulin receptor mRNA in human intestinal epithelial cells by a protein synthesis dependent mechanism. Mol. Immunol. 30:413-421.

19. Sollid, L. M., D. Kvale, P. Braentzaeg, G. Markussen, and E. Thornsby. 1987. Interferon- $\gamma$ enhances expression of secretory component, the epithelial receptor for polymeric immunoglobulins. J. Immunol. 138:4303-4306.

20. Kvale, D., P. Braentzaeg, and D. Lovhaug. 1988. Up-regulation of the expression of secretory component and HLA molecules in a human colonic cell line by tumour necrosis factor-alpha and gamma interferon. Scand. J. Immunol. 28:351-357.

21. Phillips, J. O., M. P. Everson, Z. Moldoveanu, C. Lue, and J. Mesteck. 1990. Synergistic effect of IL-4 and IFN-gamma on the expression of the polymeric Ig receptor (secretory component) and IgA binding by human epithelial cells. J. Immunol. 145:1740-1744.

22. Lim, K., and C.-B. Chase. 1989. A simple assay for DNA transfection by incubation of the cells in culture dishes with substrates for beta-galactosidase. BioTechniques. 7:576-579.

23. Glantz, S. A. 1987. Biostatistics. McGraw-Hill Company, New York. 64-100.

24. Wagner, E., M. Cotten, R. Foisner, and M. T. Birnstiel. 1991. Transferrinpolycation-DNA complexes: the effect of polycations on the structure of the complex and DNA delivery to cells. Proc. Natl. Acad. Sci. USA. 88:4255-4259.

25. Takamuri, T., and Y. Eishi. 1984. Distribution of SC and immunoglobulins in the developing lung. Am. Rev. Respir. Dis. 1318:125-130.

26. Watts, C. L., A. A. Fanaroff, and M. C. Bruce. 1992. Fibronectin levels in lung secretions in respiratory distress syndrome. J. Pediatr. 20:614-620.

27. Martinez-Tello, F. J., D. G. Braun, and W. A. Blanc. 1968. Immunoglobulin production in bronchial mucosa and bronchial lymph nodes, particularly in cystic fibrosis of the pancreas. J. Immunol. 101:989-1003.

28. Johnson, L. G., J. C. Olsen, B. Sarkadi, K. L. Moore, R. Swanstrom, and R. C. Boucher. 1992. Efficiency of gene transfer for restoration of normal airway epithelial function in cystic fibrosis. Nature Genet. 2:21-25.

29. Raphael, G. D., H. M. Druce, J. N. Baraniuk, and M. A. Kaliner. 1988. Pathophysiology of rhinitis. 1. Assessment of the sources of protein in methacholine induced nasal secretions. Am. Rev. Respir. Dis. 138:413-420.

30. Zenke, M., P. Steinlein, E. Wagner, M. Cotten, H. Beug, and M. L. Bernstiel. 1990. Receptor-mediated endocytosis of transferrin-polylysine conjugates: an efficient way to introduce DNA into hematopoietic cells. Proc. Natl. Acad. Sci. USA. 87:3655-3659.

31. Cotten, M., F. Laengle-Rouault, H. Kirlappos, E. Wagner, K. Michtler, M. Zenke, H. Beug, and M. L. Birnstiel. 1990. Transferrin-polycation-mediated introduction of DNA into human leukemic cells: stimulation by agents that affect the survival of the transfected DNA or modulate transferrin receptor levels. Proc. Natl. Acad. Sci. USA. 87:4033-4037.

32. Engelhardt, J. F., J. R. Yankaskas, S. A. Ernst, Y. Yang, C. R. Marino, R. C. Boucher, J. A. Cohn, and J. M. Wilson. 1992. Submucosal glands are the predominant site of CFTR expression in the human bronchus. Nature Genet. 2:240-247.

33. Trapnell, B. C., C.-S. Chu, P. K. Paakko, T. C. Banks, K. Yoshimura, V. J. Ferrans, M. S. Chernick, and R. G. Crystal. 1991. Expression of the cystic fibrosis transmembrane conductance regulator gene in the respiratory tract of normal individuals and individuals with cystic fibrosis. Proc. Natl. Acad. Sci. USA. 88:6565-6569.

34. Chu, C.-S., B. C. Trapnell, S. M. Curristin, G. R. Cutting, W. B. Guggino, and R. G. Crystal. 1992. Extensive posttranscriptional deletion of the coding sequences for part of nucleotide-binding fold 1 in respiratory epithelial mRNA transcripts of the cystic fibrosis transmembrane conductance regulator gene is not associated with the clinical manifestations of cystic fibrosis. J. Clin. Invest. 90:785-790. 